\title{
Earliest Christian History
}

History, Literature, and Theology. Essays from the Tyndale Fellowship in Honor of Martin Hengel

Ed. by Michael F. Bird and Jason Maston

[Frühchristliche Geschichte. Geschichte, Literatur und Theologie. Aufsätze der Tyndale Gesellschaft zu Ehren Martin Hengels.]

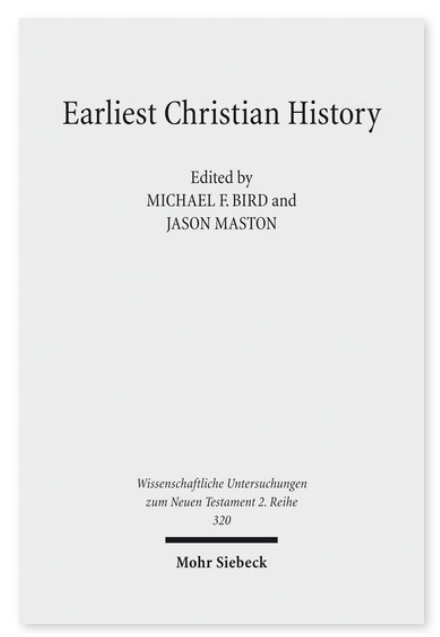

2012. XV, 681 Seiten. WUNT II 320

ISBN 978-3-16-151877-5

DOI 10.1628/978-3-16-151877-5

eBook PDF $129,00 €$

ISBN 978-3-16-151743-3

fadengeheftete Broschur 129,00€
Veröffentlicht auf Englisch.

Martin Hengel (1926-2009) war ein Historiker des frühen Christentums und des antiken Judentums. Durch seine zahlreichen Publikationen, seine Forschungsstudenten, die Teilnahme an Tagungen und seine kirchliche Arbeit gelangte er zu großem internationalem Einfluss. Sein wissenschaftliches Vermächtnis wurde mit einer Tagung geehrt, die im Juli 2010 im Tyndale House in Cambridge stattfand und zu der Gelehrte aus Deutschland, England und den USA zusammenkamen.

Die Aufsätze in diesem Band umfassen sowohl biographische Arbeiten von ehemaligen Studenten, die an Martin Hengel als akademischen Lehrer und christlichen Wissenschaftler erinnern, als auch Beiträge zur Christologie, zu den Evangelien, zum antiken Judentum und zum frühen Christentum.

Außerdem enthält der Band neue Übersetzungen von sechs von Martin Hengels wichtigsten Aufsätzen, die zum ersten Mal ins Englische übertragen wurden.

Michael F. Bird Born 1974; 2005 PhD from University of Queensland; 2005-09 New Testament Tutor at Highland Theological College; 2010-12 Lecturer in Theology at Crossway College; since 2013 Lecturer in Theology at Ridley College.

Jason Maston Born 1978; 2010 PhD from Durham University (England); Lecturer in New Testament at Highland Theological College UHI in Dingwall, Scotland.

Martin Hengel (1926-2009) was Professor of New Testament and Early Judaism at the Protestant Theology Faculty at the University of Tübingen.

Jetzt bestellen:

https://mohrsiebeck.com/buch/earliest-christian-history-9783161518775?no_cache=1

order@mohrsiebeck.com

Telefon: +49 (0)7071-923-17

Telefax: +49 (0)7071-51104 